\title{
Major depression and generalized anxiety disorder among HTLV-I/II infected former blood donors
}

\author{
Anne M Guiltinan ${ }^{1 *}$, Zhanna Kaidarova ${ }^{1}$, Dee Behan ${ }^{2}$, Cheryl Marosi ${ }^{3}$, Sheila Hutching ${ }^{4}$, Mandi Kaiser ${ }^{5}$, \\ Elane Moore ${ }^{5}$, Deborah DeVita ${ }^{1,6}$, Edward L Murphy ${ }^{1,6^{*}}$ \\ From 15th International Conference on Human Retroviruses: HTLV and Related Viruses \\ Leuven and Gembloux, Belgium. 5-8 June 2011
}

\section{Background}

Other studies have reported high rates of depression and anxiety among human T-lymphotropic virus type 1 (HTLV-1) infected subjects, and have even suggested that HTLV-I causes psychiatric disease.

\section{Methods}

We interviewed HTLV-I, HTLV-II and demographically similar HTLV seronegative blood donors with the MiniInternational Neuropsychiatric Interview (MINI). Prevalences of major depression and generalized anxiety disorder in each group were calculated and compared to published U.S. population data. Adjusted odds ratios $(\mathrm{aOR})$ and $95 \%$ confidence intervals $(95 \% \mathrm{CI})$ controlling for educational achievement, alcohol intake and selfreported health status were calculated with multivariate logistic regression.

\section{Results}

Major depression was diagnosed in $5(5.4 \%)$ of 93 HTLV-I positive subjects $(\mathrm{aOR}=2.19,95 \% \mathrm{CI} 0.63$ $7.55)$ and $17(6.6 \%)$ of 256 HTLV-II positive subjects $(\mathrm{aOR}=1.61,95 \% \mathrm{CI}$ 0.66-3.92), compared to $12(2.1 \%)$ of 585 HTLV seronegative blood donors. The prevalence of major depression among infected subjects was comparable to the $6.7 \%$ prevalence in the U.S. general population. Generalized anxiety disorder was diagnosed in 5 (5.4\%) HTLV-I positive subjects $(\mathrm{OR}=2.32,95 \% \mathrm{CI}$ 0.74-7.26) and 12 (4.7\%) HTLV-II positive subjects (OR $=1.6595 \%$ CI 0.68-4.01), compared to 15 (2.6\%) seronegatives and $3.1 \%$ in the U.S. general population.

\section{Conclusion}

We observed slightly higher prevalence of major depression and generalized anxiety disorder among HTLV-I and HTLV-II subjects that was not significantly elevated after controlling for health status and other confounding variables. Comparison to U.S. population data suggested that these findings are in part explained by a "healthy blood donor effect" among our controls.

\section{Acknowledgements}

For the HTLV outcomes study (HOST)

\section{Author details}

${ }^{1}$ Blood Systems Research Institute, San Francisco, CA 94118, USA. ${ }^{2}$ American Red Cross Blood Services, Greater Chesapeake and Potomac Region, Baltimore, MD 21215, USA. ${ }^{3}$ American Red Cross Blood Services, SE Michigan Region, Detroit, MI 48202, USA. ${ }^{4}$ American Red Cross Blood Services, Southern California Region, Pomona, CA 91768, USA. ${ }^{5}$ Oklahoma Blood Institute, Oklahoma City, OK 73104, USA. ${ }^{6}$ University of California, San Francisco, CA 94118, USA.

Published: 6 June 2011

doi:10.1186/1742-4690-8-S1-A70

Cite this article as: Guiltinan et al: Major depression and generalized anxiety disorder among HTLV-1/II infected former blood donors. Retrovirology 2011 8(Suppl 1):A70.

* Correspondence: murphy@ucsf.edu

'Blood Systems Research Institute, San Francisco, CA 94118, USA

Full list of author information is available at the end of the article

(c) 2011 Guiltinan et al; licensee BioMed Central Ltd. This is an open access article distributed under the terms of the Creative Commons 